\title{
Changing trends of causative factors in antenatal mothers with bad obstetric history: a retrospective study
}

\author{
Anu Bhargavi W. B.*, Sailatha R., Anuradha C. R. \\ Department Of Obstetrics and Gynaecology, Chettinad Hospitals and Research Institute, Kelambakkam, Chennai, Tamil \\ Nadu, India
}

Received: 23 July 2021

Accepted: 17 August 2021

\section{*Correspondence:}

Dr. Anu Bhargavi W. B.,

E-mail: anubasker94@gmail.com

Copyright: $\odot$ the author(s), publisher and licensee Medip Academy. This is an open-access article distributed under the terms of the Creative Commons Attribution Non-Commercial License, which permits unrestricted non-commercial use, distribution, and reproduction in any medium, provided the original work is properly cited.

\section{ABSTRACT}

Background: The death of an infant, in utero or after birth has been a devastating experience for parents and clinicians alike. Various efforts are being made to make an accurate diagnosis of such pregnancy losses at the earliest to prevent the emotional and physical stress that the woman undergoes. This study aims to assess the changing trends in risk factors and outcome of pregnancies in cases of bad obstetric history $(\mathrm{BOH})$ and to identify the newly emerging maternal and fetal factors contributing to incidence of pregnancy loss.

Methods: This study is a retrospective analysis of antenatal women with $\mathrm{BOH}$ attending the obstetrics and gynecology OPD at Chettinad hospital. The study was conducted during a time period of 1 year (May 2019 to May 2020).

Results: The medical complications and underlying causes for BOH were analysed among the study group. Out of 41 women, 6 were diagnosed to have gestational diabetes mellitus (GDM), 8 were found to be hypertensive and 1 APLA positive. Neonatal mortality was encountered in 2 cases, attributing to Inborn error of metabolism. However, the cause for $\mathrm{BOH}$ remained unexplained in 3 individuals.

Conclusions: A full work-up can be initiated after two consecutive losses to identify and treat the various causes responsible for $\mathrm{BOH}$. Lot of further studies and research are being conducted to unravel the mystery in these cases. Despite these efforts, the male factors contributing to recurrent pregnancy loss have remained largely unexplored

Keywords: Pregnancy loss, Neonatal outcome, Inborn errors of metabolism, Mode of delivery

\section{INTRODUCTION}

Pregnancy loss is a frustrating and challenging problem for both couples and clinicians. Miscarriage is often associated with great deal of emotional impediment, especially when it happens on a repetitive basis. ${ }^{1}$ Detailed evaluation of women with $\mathrm{BOH}$ has revealed the underlying contributing factor in $40-50 \%$ cases. Antenatal women with history of two or more consecutive spontaneous abortions, early neonatal deaths, stillbirths, intrauterine fetal deaths, Intrauterine growth retardation or congenital anomalies in the fetus are considered high risk and monitored accordingly.
The incidence of $\mathrm{BOH}$ among the general population is about $1-2 \%{ }^{2}$ Studies show that the probability of a conception ending in miscarriage is about $12-15 \%{ }^{3}$ The risk of miscarriages in subsequent pregnancies is $30 \%$ after 2 losses, compared with $33 \%$ after 3 losses among patients without a history of a live birth. ${ }^{4}$ Hence the evaluation of patients with 2 pregnancy losses and no prior live birth plays an important role.

The cause of $\mathrm{BOH}$ is multifactorial which include parental chromosomal abnormalities, structural uterine anomalies, endocrine factors, thrombophilia, antiphospholipid antibody syndrome, immunological factors, environmental factors etc. Approximately $2-4 \%$ is 
contributed to parental chromosomal abnormalities, anatomical causes contribute to $10 \%-15 \%$, while other causes like endocrine-17-20\%, antiphospholipid antibody syndrome to $15 \%-20 \% .{ }^{4}$ However, the underlying cause remains unknown in $33 \%$ cases. $^{4}$

\section{Aim of the study}

The aim of the study was to assess the recent trends in risk factors and outcome of pregnancies in cases of $\mathrm{BOH}$ and to identify the various maternal and fetal factors contributing to incidence of pregnancy loss. The maternal factors contributing to pregnancy loss was analysed in terms of-age, BMI, gravidity, parity, presence of conditions such as parental chromosomal anomalies, maternal thrombophilic disorders (APLA) structural uterine anomalies, hypothyroid, gestational diabetes mellitus, hypertension, premature rupture of membranes, antepartum haemorrhage, cervical incompetence, tuberculosis. The fetal outcomes of interest are prematurity, fetal anomalies (structural/chromosomal), Intra uterine growth retardation (IUGR), inborn error of metabolism (IEM), stillbirth, mode of delivery, birth weight, fetal distress, meconium-stained liquor.

\section{METHODS}

This study is a retrospective analysis of antenatal women with $\mathrm{BOH}$ attending the obstetrics and gynecology out patient department at Chettinad hospital. The study was conducted during a time period of 1 year (May 2019 to May 2020). The records of the patients satisfying the inclusion and exclusion criteria was obtained from the medical records department.

\section{Inclusion criteria}

Inclusion criteria for the study were- $\geq 2$ consecutive spontaneous abortions, $\geq 2$ early neonatal deaths, $\geq 2$ stillbirths, $\geq 2$ intrauterine fetal deaths, $\geq 2$ intrauterine growth retardation, $\geq 2$ congenital anomalies in the fetus, and combination of any $\geq 2$ of the above.

\section{Exclusion criteria}

Exclusion criteria for the study were-induced abortions, previous uneventful deliveries (vaginal/LSCS). After getting informed consent of participants included in the study telephonically and ethical committee approval. Based on the inclusion and exclusion criteria, 41 patients were included in the study. The medical complications and underlying causes for $\mathrm{BOH}$ were analysed among the study group. Fetal outcomes such as prematurity, Fetal anomalies (structural/chromosomal), Intra uterine growth retardation (IUGR), inborn error of metabolism (IEM), stillbirth, mode of delivery, birth weight, Fetal distress, Meconium-stained liquor were also analysed. All the above data were analysed using SPSS software.

\section{RESULTS}

In our study, nearly $67.3 \%$ of women belonged to age between 20-30 years, with a mean age of about 28.56 \pm 2.79 $\mathrm{SD}$. The mean BMI of women included in the study was 23.2 \pm 2.07 SD (Table 1).

Table 1: Maternal factors.

\begin{tabular}{|lll|}
\hline Variables & Mean & SD $( \pm)$ \\
\hline Age (years) & 28.56 & 2.79 \\
\hline BMI & 23.2 & 2.07 \\
\hline Parity & 1.24 & 0.70 \\
\hline Birth weight & 2.88 & 0.48 \\
\hline
\end{tabular}

Out of 41 women, 6 were diagnosed to have gestational diabetes mellitus (GDM), 8 were found to be hypertensive and 1 APLA positive. The cause for recurrent neonatal death was thought to be but on evaluation found to have been due to inborn errors of metabolism-isovaleric acidemia in one and fatty acid oxidation defect in another. However, the cause for $\mathrm{BOH}$ remained unexplained in 3 individuals (Table 2).

In our study, we found that $65 \%$ women delivered by caesarean section while $29.2 \%$ delivered vaginally and $0.04 \%$ by VBAC (Table 3 and 4 ).

Various fetal outcomes such as preterm delivery, IUGR, stillbirth, MSL, IUD and neonatal morbidities and mortalities were noted. The incidence of MSL was $31.7 \%$ while preterm delivery accounted for about $21.9 \%$. Neonatal mortality was noted in $4.8 \%$ of the cases. However, $41.4 \%(n=17)$ had good fetal outcome (Table 5).

About $43.9 \%$ women were gravida 4 , whereas $31.7 \%$, $9.7 \%, 14.6 \%$ women were gravida 3,5 and 6 respectively. (Table 6).

Table 2: Medical complications/underlying causes.

\begin{tabular}{|l|l|}
\hline $\begin{array}{l}\text { Medical complications/underlying } \\
\text { causes }\end{array}$ & N \\
\hline APLA & 1 \\
\hline Hypothyroid & 8 \\
\hline Tuberculosis (tb) & - \\
\hline Gestational diabetes mellitus (GDM) & 6 \\
\hline Pre-eclampsia & 8 \\
\hline Luteal phase defect & - \\
\hline Hyperprolactinemia & - \\
\hline Parentral chromosomal anomalies & - \\
\hline $\begin{array}{l}\text { Prelabour rupture of membranes } \\
\text { (prom) }\end{array}$ & 6 \\
\hline Antepartum haemorrhage (APH) & 1 \\
\hline Malpresentation & 4 \\
\hline Cervical incompetence & 2 \\
\hline Inborn error of metabolism & 2 \\
\hline Unexplained & 3 \\
\hline
\end{tabular}


Table 3: Mode of delivery.

\begin{tabular}{|ll|}
\hline Mode of delivery & N \\
\hline LSC & \\
\hline Overall & 27 \\
\hline Elective & 9 \\
\hline Emergency & 18 \\
\hline Vaginal delivery & \\
\hline Overall & 12 \\
\hline Normal vaginal delivery & 10 \\
\hline Vacuum assisted & 2 \\
\hline Forceps & - \\
\hline VBAC & 2 \\
\hline
\end{tabular}

Table 4: Indications for elective and emergency LSCS.

\begin{tabular}{|c|c|c|c|}
\hline \multicolumn{2}{|l|}{ Emergency LSCS } & \multicolumn{2}{|l|}{ Elective LSCS } \\
\hline Indication & $\mathrm{N}$ & Indication & $\mathrm{N}$ \\
\hline $\begin{array}{l}\text { Failure to } \\
\text { progress }\end{array}$ & 1 & Malpresentation & 2 \\
\hline Fetal distress & 2 & $\mathrm{BOH}$ & 2 \\
\hline Failed induction & 2 & Previous LSCS & 5 \\
\hline $\mathbf{A P H}$ & 1 & Total & 9 \\
\hline Previous LSCS & 5 & & \\
\hline $\begin{array}{l}\text { Multiple } \\
\text { pregnancy }\end{array}$ & 1 & & \\
\hline Pre-eclampsia & 2 & & \\
\hline Malpresentation & 2 & & \\
\hline Total & 18 & & \\
\hline
\end{tabular}

Table 5: Fetal outcome.

\begin{tabular}{|lll|}
\hline Variables & N & Percentage $(\%)$ \\
\hline Preterm & 9 & 21.9 \\
\hline IUGR & - & - \\
\hline Stillbirth & - & - \\
\hline Msl & 13 & 31.7 \\
\hline $\begin{array}{l}\text { Neonatal mortality } \\
\text { and morbidity }\end{array}$ & 2 & 4.8 \\
\hline IUD & - & - \\
\hline
\end{tabular}

Table 6: Parity wise distribution.

\begin{tabular}{|lll|}
\hline Parity & N & Percentage (\%) \\
\hline $\mathbf{G}_{3}$ & 13 & 31.7 \\
\hline $\mathbf{G}_{\mathbf{4}}$ & 18 & 43.9 \\
\hline $\mathbf{G}_{\mathbf{5}}$ & 4 & 9.7 \\
\hline $\mathbf{Z}$ G & 6 & 14.6 \\
\hline
\end{tabular}

\section{DISCUSSION}

The attempt to identify the underlying cause for recurrent pregnancy losses has led to revelation of contributing factor in about $40-50 \%$ of women. Even in couples where no underlying problem is found, the chances for a successful pregnancy can typically be in the $50-70 \%$ range. ${ }^{1}$
In our study, $7.3 \%$ of women had no underlying medical complication contributing to $\mathrm{BOH}$. Anand et al showed that incidence of low-birth-weight baby was 4 times more among women with BOH. ${ }^{5}$ However in our study, $31.6 \%$ of babies born to mothers with $\mathrm{BOH}$ were low birth weight, the mean birth weight being $2.88 \pm 0.48$ SD.

The incidence of gestational hypothyroidism leading to suboptimal obstetric outcomes is around $1 \% .{ }^{6}$ Our study showed an increase in the incidence of gestational hypothyroidism of about $21.9 \%$.

Deodhar et al and Surkan et al showed high incidence of hypertension in $\mathrm{BOH}$ group as also seen in our study $(19.5 \%){ }^{8}$

2 out of 41 women had history of mid-trimester abortions in previous pregnancy strongly suggestive of cervical incompetence, hence prophylactic cervical encircle (McDonald suture) was done in these patients.

Previous studies by Hughes et al reported an increased incidence of gestational diabetes mellitus while we were unable to confirm such a finding in our study. (14.63\%) ${ }^{9}$

Increase in BMI has led to higher incidence of peripartum complications such as preterm birth, caesarean delivery and GDM, however the mean BMI of our study group was around 23.2 \pm 2.07 SD. ${ }^{10}$

Antiphospholipid syndrome and APLA is now increasingly recognized as being an important cause of $\mathrm{BOH}$ leading to early miscarriages and thus emphasizing the need for antibody screening of women with pregnancy loss. ${ }^{11}$ The prevalence of APLA positivity in women with $\mathrm{BOH}$ is $10-46 \% .^{12}$ However, Incidence in our study was about $2.4 \%$.

Further evaluation of neonatal death of unknown cause revealed the association between inborn errors of metabolism such as isovaleric acidemia and Fatty acid oxidation defect accounting to about $4.8 \%$ in our study. While Unrecognized metabolic disorders especially, remain a preventable cause of maternal and neonatal mortality and morbidity, recent studies have managed to fill the gap in literature, exploring the unanswered questions on the association between inborn errors of metabolism and pregnancy loss. ${ }^{13}$

In our study, 4 out of 41 women had malpresentation (9.7\%), however only two among them had underlying uterine anomaly (uni-cornuate uterus and arcuate uterus).

About $21.9 \%$ women delivered $<36$ weeks of gestation $(n=9)$ out of which 3 women delivered at 32-33 weeks of gestation. Premature rupture of membranes (PROM), a risk factor for preterm delivery and neonatal infections were noted in $17 \%$ of women. 
Meconium-stained liquor (MSL) was reported in $31.7 \%$ $(n=13)$ of newborns of which 6 newborns required resuscitation. However, the fetal outcome in our study group was found to be good.

In our study, we found that $65 \%$ women delivered by caesarean section while $29.2 \%$ delivered vaginally and $0.04 \%$ by VBAC. Out of the $65 \%$ women who underwent caesarean section, $33.3 \%$ were planned whereas $66.6 \%$ were emergency caesarean sections. Vaginal delivery was accomplished in $29.2 \%(n=12)$ of the women, however 2 among the 12 required vacuum assistance due to poor maternal effort.

In this study, only $30(73.17 \%)$ women out of 41 were identified to have possible factors responsible for pregnancy losses. In 8 (19.5\%), 7 women had PROM, 1 had APH, both being probable indirect causes for $\mathrm{BOH}$, while the cause of recurrent pregnancy loss was unexplained in $3(7.3 \%)$.

\section{Limitations}

Paternal factors which may attribute to the bad obstetric outcome could not be ruled out, since it is a retrospective study.

\section{CONCLUSION}

A full work-up can be initiated after two consecutive losses to identify and treat causes that include endocrine causes, APLA, uterine anomalies, balanced translocations etc. Implementation of lifestyle modification should go hand in hand. Inborn errors of metabolism should be considered in the diagnosis of any sick neonate along with common acquired causes to aid parents plan future pregnancy. Newer approaches such as preimplantation genetic diagnosis (PGD) followed by artificial reproductive technique (ART) may be done. In spite of various attempts to diagnose and treat the cause, almost half the cause of $\mathrm{BOH}$ remains unexplained. Lot of further studies and research are being conducted to unravel the mystery in these cases. Recent studies have revealed the role of paternally expressed genes in trophoblastic invasion and placental proliferation which may affect the pregnancy in early embryogenesis. Despite these efforts, the male factors contributing to Recurrent pregnancy loss have remained largely unexplored.

Funding: No funding sources Conflict of interest: None declared

Ethical approval: The study was approved by the Institutional Ethics Committee

\section{REFERENCES}

1. Col Singh G, Maj Sidhu K. Bad Obstetric History: A Prospective Study. MJAFI. 2010;66:117-20.

2. Koppad C, KSL. Immunological causes of bad obstetric history. J Evidence Based Med Healthcare. 2014;1(16):2086-99.

3. Devi R, Sreenivas N, Rajangam S. Bad Obstetric History and Infectious Causes. Int J Human Genetics. 2002;2(4):269-71.

4. Singh A, Kujur A, Rathore K. An evaluation of recurrent pregnancy loss. Int J Reproduction, Contraception, Obstetrics Gynecol. 2017;6(4):1332.

5. Anand K, Garg BS. A Study of Factors Affecting LBW. Indian J Community Med. 2000;25:4-6.

6. Aziz N, Reddy P, Fernandez E. Hypothyroidism in pregnancy: Is universal screening needed? J Obstet Gynecol India. 2006;56:495-8.

7. Deodhar J, Jarad R. Study of the prevalence of and high-risk factors for fetal malnutrition in term newborns. Ann Trop Paediatr Int Child Health. 1999;19:273-7.

8. Surkan PJ, Stephansson O, Dickman PW, Cnattingius S. Previous Preterm and Small-for-Gestational-Age Births and the Subsequent Risk of Stillbirth. N Engl J Med. 2004;350(8):777-85.

9. Hughes N, Hamilton E, Tulandi T. Obstetric outcome in women after multiple spontaneous abortions. $\mathbf{J}$ Reprod Med. 1991;3:165-6.

10. Smith GCS, Shah I, Pell JP, Crossley JA, Dobbie R. Maternal Obesity in Early Pregnancy and Risk of Spontaneous and Elective Preterm Delivery. A Retrospective Cohort Study. Am J Public Health. 2007;97:157-62.

11. Noble, Luis S. Antiphospholipid antibodies associated with recurrent pregnancy loss prospective, multicenter, controlled pilot study comparing treatment with low-molecular-weight heparin versus unfractionated heparin. Fertility sterility. 2005;83(3):684-90.

12. Vora S, Shetty S, Salvi V, Satoskar P, Ghosh K. A comprehensive screening analysis of antiphospholipid antibodies in Indian women with fetal loss. Euro J Obstetr Gynecol Reproduct Biol. 2008;137(2):13640.

13. Wilcox G. Impact of pregnancy on inborn errors of metabolism. Reviews Endocrine Metabolic Disorders. 2018;19(1):13-33.

Cite this article as: Bhargavi AWB, Sailatha R, Anuradha CR. Changing trends of causative factors in antenatal mothers with bad obstetric history: a retrospective study. Int J Reprod Contracept Obstet Gynecol 2021;10:3371-4. 